Agro-Science Journal of Tropical Agriculture, Food, Environment and Extension Volume 18 Number 2 (May 2019) pp. 26-31

ISSN 1119-7455

\title{
THE EFFECT OF WATER SOURCES, NUTRITIONAL QUALITIES AND MANAGEMENT SYSTEMS ON THE PREVALENCE OF GASTROINTESTINAL HELMINTH INFECTIONS IN RUMINANTS IN BENUE STATE, NIGERIA
}

\author{
${ }^{1}$ Tikyaa, G.N., ${ }^{1}$ Oke, P.O., ${ }^{2}$ Ikpa, T.F. and ${ }^{2}$ Imandeh, G.N. \\ ${ }^{1}$ Department of Veterinary Parasitology and Entomology, \\ Federal University of Agriculture, Makurdi, PMB 2373 Makurdi, Nigeria \\ ${ }^{2}$ Department of Zoology, Federal University of Agriculture, Makurdi, PMB 2373 Makurdi, Nigeria \\ Corresponding author's email: tfikpa@gmail.com
}

\begin{abstract}
Parasitic helminth infections are a frequent burden to livestock farmers. In this study, some domestic ruminants were examined for gastrointestinal helminth infections at some locations in Benue State Nigeria. Six hundred faecal samples were collected per rectum from cattle, goat and sheep in Makurdi, Guma and Gboko. The faeces were analysed using Concentration Method, and direct microscopic examination of helminth parasites. Data were also obtained on the source of drinking water, feeding, and the management system used to keep the ruminants. The results showed that $43.7 \%$ of all animals were infected. The species of helminth parasites identified were Strongyloidesspp. 74.8\% Haemonchusspp., 11.8\% whileMoniezaspp., Trichuris spp., Taeniaspp.,Fasciolaspp., Ascaris spp., and Toxocaraspp., constituted 13.4\%. Helminths infection was associated with the type of animal $(p=0.01)$, the source of drinking water $(p<0.001)$, food, and the management system $(p<0.001)$, but not the sampled locations $(p=0.98)$. It was concluded that improved management practices, provision of good quality food and clean drinking water significantly reduced the prevalence of gastrointestinal helminths infection in ruminants in Benue State, Nigeria.
\end{abstract}

Key words: gastrointestinal helminths, parasites, ruminants, livestock

\section{INTRODUCTION}

Meat from ruminants are very important to human nutrition in a largely agrarian economy like Nigeria, they have the potential of serving as tools for poverty reduction. These animals play a vital role in rural economies through the provision of meat, milk, household income, manure and skins. In Nigeria, human food needs such as meats and dairy products are frequently obtained from ruminant animals such as cattle, sheep and goats. They serve as important sources of animal proteins forman (Owhoeli et al., 2014). The cattle for instance is widely distributed and reared in many parts of Nigeria; and its products consumed by many people (Anene et al., 1994). In addition, sheep and goats are equally reared and widely slaughtered at abattoirs in Nigeria, where they are sold to the public. Apart from these animals being a source of animal proteins, their wastes are also used as manure in agriculture (Nwosu et al., 2007). Parasitic diseases, particularly those caused by helminths, coupled with inadequate management practices by livestock farmers hamper the productivity of these animals. In many farms, high prevalence of gastro-intestinal helminth parasites usually constitute a serious impediment to small animal production in Nigeria. Very often, the gastro-intestinal tracts (GITs) of these livestock frequently harbour a variety of helminths, which cause clinical and subclinical parasitism (Regassa et al., 2006), that sometimes lead to high mortality, low productivity and significant economic losses to the livestock industry. Milk production is negatively impacted as it dwindles due to helminths infection in cattle. Some important risk factors that might promote helminth infections are sometimes overlooked by the farmers keeping these animals. Some of these risk factors include grazing or feeding habits, nutritional deficiency, pasture management, immunological status, presence of intermediate hosts and vectors, number of infective larvae and eggs released into the environment, and a conducive weather condition for the development of the helminth's eggs to infective stages (Odoi et al.,2007). Most medium and large-scale farmers

Please cite as: Tikyaa, G.N., Oke, P.O., Ikpa, T.F. and Imandeh, G.N. (2019). The effect of water sources, nutritional qualities and management systems on the prevalence of gastrointestinal helminth infections in ruminants in Benue State, Nigeria. Agro-Science, $\mathbf{1 8}$ (2), 26-31. DOI: https://dx.doi.org/10.4314/as.v18i2.5 
involved in small ruminant farming in Nigeria manage their ruminants either in semi-intensive or free ranging conditions. These systems of rearing expose the ruminants to multiple risks, culminating to infections, which in turn reduces profitability due to increased costs of treatment, and even death of the animals (Fabiyi et al., 1973). Gastrointestinal parasitic infections of ruminants are worldwide in nature; however, their adverse effect is most felt in Sub-Saharan Africa due to the availability of a wide range of agro-ecological factors suitable for the definitive host and survival of the parasites and its intermediate hosts (Fabiyi et al., 1973). Helminth infections in ruminants contribute significantly to livestock mortality in Nigeria; it is also believed to contribute to human morbidity in the country (Karshima et al., 2018). The free ranging animals that openly graze are mostly susceptible to helminth infection, as open grazing of pastures expose the animals to graze very close to faecal materials, where the concentration of helminths infective stages are very high (Mondal et al., 2000). Like most livestock farmers elsewhere in Nigeria, framers in Benue State frequently underestimate the importance of providing clean drinking water, good quality food, and a decent housing environment for their livestock. There fore, this study was undertaken to determine the effect of sources of drinking water, quality of food and type of management systems on the prevalence of gastrointestinal helminths infection in ruminants reared in Benue State Nigeria.

\section{MATERIALS AND METHODS}

\section{Study Area}

The study areas were Makurdi, Gboko and Guma Local Government Areas of Benue State (Figure 1). Benue State is popular for breeding as well as consumption of meats from cattle, sheep and goats. The State borders with Nasarawa State to the north and Taraba State to the east from where most of the animals are moved into the state to augment the high demand for meat. The State also borders with Cross-River State to the south, Enugu State to the South-west, Kogi State to the west and shares international boundary with the republic of Cameroon to the South east.

\section{Faecal and Sample Collection}

Samples for the study were collected from the Makurdi cattle market, and the veterinary clinic, University of Agriculture Teaching Hospital, Makurdi. Samples were also collected from Gbajimba in Guma Local Government Area and the College of Agriculture Yandev in Gboko Local Government Area. Faecal samples were collected per rectum using hand gloves into sterile bottles. All the specimens were clearly identified, labeled and kept in an ice box and transported to the
Veterinary Parasitology Laboratory of the Federal University of Agriculture Makurdi, and processed immediately. The study lasted for five (5) months from the dry season in January to the beginning of rainy season in May, 2017.

\section{Sample Processing, Microscopic Examination and Identification of Helminth Parasites}

Faecal samples were processed and examined for the presence of helminth eggs and larvae using simple faecal centrifugation floatation technique (Foryet, 2001). Briefly, $2 \mathrm{~g}$ of faeces were mixed with $60 \mathrm{ml}$ of sugar solution; the samples were then strained through a tea strainer into test tubes and single-step centrifugation was carried out at 300 rpm for 10 minutes (Weber992). A plastic pipette was used to pick few drops of the samples from the top layer for a wet mount smear on a microscope slide and observed under a microscope for eggs and larvae using X10 and X40 objectives lens. Identification of parasitic eggs and larvae was carried out based on the morphology and size (Kassai, 1999). In each case, the parasite stage was photographed using Celestron LCD digital microscope model 44340. Faecal samples were also examined for adult parasites by direct smear and concentration method using Formol-ether concentration technique and saturated salt floatation method by Urquahart et al. (1996).

\section{Interviews to the Livestock Farmers}

For each animal from which faecal samples were taken, the owners were asked to provide information on the mode of feeding and the source of water given to the animal, as well as the farm management practice used in keeping the animal. The data obtained for each animal were recorded using an identification number assigned to each of the animal from the three sample locations.

\section{Ethical Consideration}

The study was approved by the ethics committee of Veterinary Teaching Hospital, College of Veterinary Medicine, Federal University of Agriculture Makurdi. Consent to collect faecal samples from the animals was given by their owners.

\section{Data Analysis}

The Chi-Square $\left(\square^{2}\right)$ test was used to test for association using the SPSS software version 20 . The level of significance was defined as $\mathrm{p}<0.05$.

\section{RESULTS}

The study showedthat $43.7 \%$ of all the ruminants examined had gastrointestinal helminth infections while $56.3 \%$ had no detectable infection. Sheep were the most vulnerable to helminth parasites, $49.0 \%$ while goats suffered the least infection, $40.5 \%$ However, there was no significant difference 
in the rate of helminth infection among the ruminant species $\left(\square^{2}=3.51\right.$, df $=2, \mathrm{p}=0.17$, Table 1). Eight (8) different species of helminth parasites were identified infecting all species of ruminant in varying proportions (Plates 1a-c). The most prevalent helminth parasite was Strongyloides spp which accounted for $74.8 \%$ of all helminth infections in the three groups of animals. Haemonchus spp had prevalence of $11.8 \%$ and showed a slight bias towards sheep, while other parasites including Taenia spp, Fasciola spp, Ascaris spp, Toxocara spp, Monieza spp, and Trichuris spp, were each present in small proportions, either as single or mixed in fections, with Strongyloides spp. These species of parasites accounted for the remaining $13.4 \%$. There was an association between helminth parasite species and the type of ruminant animals infected ( $\square^{2}=12.61$, $\mathrm{df}=4, \mathrm{p}=0.01$, Table 2). Taenia spp, Fasciola spp, Ascaris spp, Toxocaraspp, Monieza spp, and Trichuris spp. All the three species of ruminants examined from the three sampled locations recorded a high relative rate of helminth infection. Makurdi and Gboko each had $44.0 \%$ while Guma, had $43.0 \%$ However, the rate of helminth infection in the animals based on location was not significantly different $\left(\square^{2}=3.51\right.$, df $=2, \mathrm{p}=0.98$, Table 3). Analysis of the data on the source of drinking water for the animals showed that ruminants that drank well water had higher helminth infection rate of $48.9 \%$ compared to $41.6 \%$ of those that drank from the stream water, and $24.2 \%$ of those that drank pipe born water. The rate of infection was associated with the source of drinking water $\left(\square^{2}=13.45\right.$, df $=2, \mathrm{p}=0.001$, Figure 2). The prevalence of helminth infections among animals that fed through open grazing was $48.8 \%$ compared to $19.8 \%$ among ruminants that were fed processed food. There was a strong association with the source of feeding and the rate of helminth infections in the ruminants $\left(\square^{2}=\right.$ 29.78, df $=2, p<0.0001$, Table 4). A similar strong association of helminths infection was observed with the management system used in keeping the ruminants, the intensive system had lower rate of infection compared to either the semiintensive or the free-range system which had the highest rate of helminths infection among the ruminants ( $\square^{2}=54.82$, df $=2, \mathrm{p}<0.001$, Table 5).

\section{DISCUSSION}

The study showed a ubiquitous high rate of helminths infection in all the three locations and species of ruminant animals examined in Benue state, which suggests that helminth is a common challenge faced by livestock farmers in the State. This evidence is particularly glaring, given that the prevalence of infection among the three sampled areas despite being very high, was not significantly different among the locations.

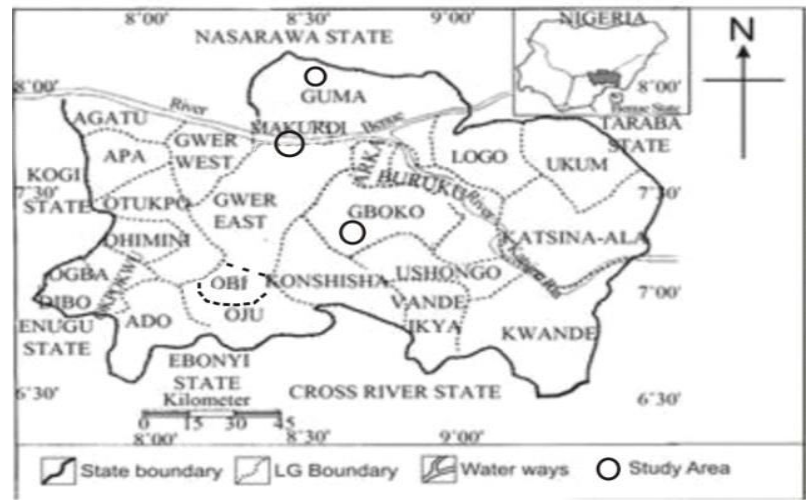

Figure 1: Map of Benue State showing the Study Areas

Table 1. Prevalence of helminth parasites in some species of ruminants in Benue State

\begin{tabular}{llll}
\hline $\begin{array}{l}\text { Ruminant } \\
\text { species }\end{array}$ & $\begin{array}{l}\text { Infected } \\
(\%)\end{array}$ & $\begin{array}{l}\text { Not infected } \\
(\%)\end{array}$ & $\begin{array}{l}\text { Total } \\
(\%)\end{array}$ \\
\hline $\begin{array}{l}\text { Bos taurus } \\
\text { (cattle) }\end{array}$ & $83(41.5)$ & $117(58.5)$ & $200(100.0)$ \\
$\begin{array}{l}\text { Capra hircus } \\
\text { (goat) }\end{array}$ & $81(40.5)$ & $119(59.5)$ & $200(100.0)$ \\
$\begin{array}{l}\text { Ovisaries } \\
\text { (sheep) }\end{array}$ & $98(49.0)$ & $102(51.0)$ & $200(100.0)$ \\
Total $(\%)$ & $262(43.7)$ & $338(56.3)$ & $600(100.0)$ \\
\hline$\square^{2}=3.51, \mathrm{df}=2, \mathrm{p}=0.17$ & &
\end{tabular}

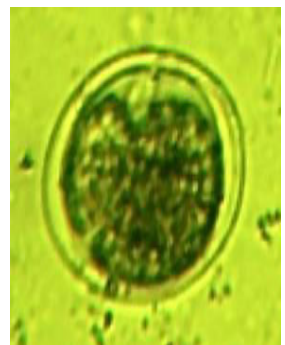

(A)

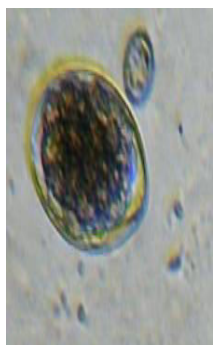

(b)

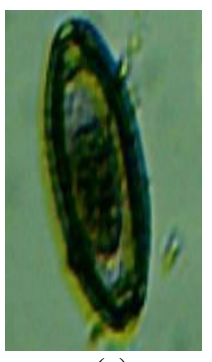

(c)
Plate 1: Ova of (a) Strongyloides spp., (b) Haemonchusspp., (c) Trichuris spp

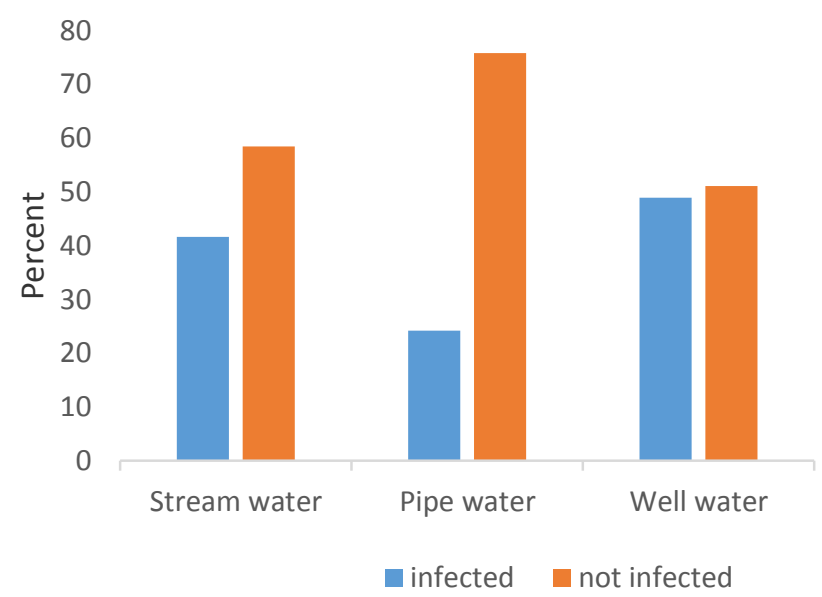

Figure 2. Association of helminths infection in ruminants with the Source of drinking water in Benue State Nigeria 
Table 2: Association of helminth species with the type of ruminant

\begin{tabular}{lllll}
\hline Helminth species & \multicolumn{2}{l}{ Type of ruminant infected with helminths } & \multirow{2}{*}{ Total infected (\%) } \\
\cline { 2 - 3 } & Cattle $(\%)$ & Goat $(\%)$ & Sheep $(\%)$ & \\
\hline Strongyloidesspp & $69(35.2)$ & $61(31.1)$ & $66(33.7)$ & $196(100.0)$ \\
Haemonchusspp & $2(6.4)$ & $10(32.3)$ & $19(61.3)$ & $31(100.0)$ \\
Other parasites* & $12(34.3)$ & $10(28.6)$ & $13(37.1)$ & $35(100.0)$ \\
Total (\%) & $83(31.7)$ & $81(30.9)$ & $98(37.4)$ & $262(100.0)$ \\
\hline
\end{tabular}

]$^{2}=12.61, \mathrm{df}=4, \mathrm{p}=0.01, \quad *$ other parasites:

Table 3: Prevalence of helminth infection in ruminantsbased on location

\begin{tabular}{llll}
\hline Location & $\begin{array}{l}\text { Infected } \\
(\%)\end{array}$ & $\begin{array}{l}\text { Not infected } \\
(\%)\end{array}$ & Total $(\%)$ \\
\hline Makurdi & $88(44.0)$ & $112(56.0)$ & $200(100.0)$ \\
Guma & $86(43.0)$ & $114(57.0)$ & $200(100.0)$ \\
Gboko & $88(44.0)$ & $112(56.0)$ & $200(100.0)$ \\
Total $(\%)$ & $262(43.7)$ & $338(56.3)$ & $600(100.0)$ \\
\hline
\end{tabular}

$\square^{2}=3.51, \mathrm{df}=2, \mathrm{p}=0.17$

Table 4: Association of helminth infection in ruminants with the source of food

\begin{tabular}{llll}
\hline food source & $\begin{array}{l}\text { Infected } \\
(\%)\end{array}$ & $\begin{array}{l}\text { Not infected } \\
(\%)\end{array}$ & Total (\%) \\
\hline Open grazing & $241(48.8)$ & $253(51.2)$ & $494(100.0)$ \\
processed & $21(19.8)$ & $85(80.2)$ & $106(100.0)$ \\
Total $(\%)$ & $262(43.7)$ & $338(56.3)$ & $600(100.0)$ \\
\hline$\square^{2}=29.78, \mathrm{df}=1, \mathrm{p}<0.001$ & &
\end{tabular}

Table 5: Association of helminths infection with the management system

\begin{tabular}{llll}
\hline $\begin{array}{l}\text { Ruminant } \\
\text { management } \\
\text { system }\end{array}$ & $\begin{array}{l}\text { Infected } \\
(\%)\end{array}$ & Not infected & Total (\%) \\
\hline Semi intensive & $95(38.8)$ & $150(61.2)$ & $245(100.0)$ \\
Intensive & $19(18.1)$ & $86(81.9)$ & $105(100.0)$ \\
Free ranging & $148(59.2)$ & $102(40.8)$ & $250(100.0)$ \\
Total $(\%)$ & $262(43.7)$ & $338(56.3)$ & $600(100.0)$ \\
\hline
\end{tabular}

$\square^{2}=54.82, \mathrm{df}=2, \mathrm{p}<0.001$

This lack of significant difference indicates a common degree of helminths infection prevailing in the sampled areas which may also apply to other locations in the state, where ruminants are kept. The prevalence of $43.7 \%$ helminth infections obtained in the present study is however relatively low compared to the prevalence elsewhere of $96.4 \%$ and $80.0 \%$ that was recorded in Minna in 2012 and 2013 respectively (Ibukun and Oludunsin 2015). Minnais an area equally located in North central Nigeria, like Benue State, with some similar ecological conditions. In a clement humid and warm ecological environment suitable for the development of helminths eggs, a high rate of helminths infection is expected, but a lot of other factors may have interplayed to warrant the rate of infection obtained in this study. One factor may be the management system used in keeping the livestock. Most of the livestock owners in the study area are known to practice free-range or semiintensive system of husbandry where animals are housed together with little or no proper care and management. These systems are prone to increase in the degree of pasture contamination, and drinking water with worm eggs, thus frequently exposing the animals to helminth. Evidently, there was a strong association between the farm management system and the rate of helminth infections. This was evident from the result of the study which showed the helminth infection rate of $59.2 \%, 38.8 \%$ and $18.1 \%$ of ruminants, reared under free range, semi intensive and intensive system of management respectively. Needless to re-emphasize that animals reared under intensive management systems are normally kept in better hygienic environments with good veterinary services and proper medications. As a result, animals kept under intensive management system were better protected from undue exposure to the unwholesome conditions that aided higher rates of helminth infections in the other systems of management. The association of the rate of helminth infections in the ruminants with the type of food shows that ,the quality of food eaten by the seanimals was a significant factor that contributed to the high rates of helminth infections observed in this study. Processed food which showed lower rate of infection than open grazing is most appropriate for intensive management of livestock. Moreover, the cost of procurement of processed feed may be prohibitive to lives to ckowners and hence the open grazing as practiced by most of the farmers. The latter which exposes the animals most frequently to food contaminated with the infective stages of helminths as open grazing increases the chance of the animals picking up the cyst, larvae and/ or intermediate host of any gastrointestinal helminth attached to the pasture. Good nutritional status of a host can positively influence the pathogenesis of helminthic infection. This is possibly the reason why the animals fed with processed feed did not present clinical signs of helminth infections. However, it can be argued that this again depends on the system chosen to rear the animals which is also dependent on the financial capacity of the farmer. Drinking water was also associated with the rate of helminths infection in the ruminant, implying that the quality of drinking water also had a significant effect on the rate of helminths infection in the ruminants. The observation that animals that drank well water had higher prevalence of helminth infection could be explained on the assumption that most shallow wells where drinking water was obtained for the animals served as a reservoir of helminth eggs released in faeces. Since wells are a stagnant reservoir of water, they may end up accumulating 
more helminth eggs than flowing streams which may disperse them. This may explain why animals that drank well water had relatively higher rate of helminths infection compared to those that drank from the stream or pipe borne water. On the basis of helminths infection observed among the ruminants, sheep had the higher prevalence of infection than cattle and goats. This observation correlates the works in parts of East Africa by Waruiru et al. (2005) that sheep is most commonly infected by parasites than goats and cattle due to the grazing habits of sheep. Kanyari et al. (2009)observed that the grazing habits of sheep closer to the soil expose them to more helminth infection than goats and cattle. However, this observation differs from the findings of Ogudoet al. (2015) in Abeokuta South Western Nigeria, where higher parasite prevalence was recorded in goats. The reason for the present findings could be due to slow development of immunity in sheep to some species of gastrointestinal parasites compared to either cattle or goat (N'Depo 2004). Given that the prevalence of helminth parasitic infections was associated with the type of animal in this study, it is possible that the slow development of immunity to Haemonchus spp., in particular may explain the higher vulnerability of sheep to the parasite $(61.3 \%)$, and perhaps account for why sheep were the most infected ruminants in this study. The high rate of Haemonchusspp recorded in sheep, has been previously observed by N'Depo (2004) and Ibukun and Oludunsin, (2015). According to Tsotetsi and Mbati (2003) the high fecundity of Haemonchussp pensures that the larvae are ingested mostly by the sheep due to the ability of the sheep to brows very close to the soil.

The preponderance of Strongyloidesspp infections among the three species of ruminants recorded in this study makes it a major hindrance to livestock farmers in Benue State. In contrast however, Strongyloidesspp., was never isolated in Minna, North Central Nigeria(Ibukun and Oludunsin 2015). The high prevalence of Strongyloidesspp., may be as a result of the favourable environmental condition that favours the development of the infective stages of the parasite. This could also be attributed to the high fecundity of the parasite which enables them to be easily picked up. Another factor could be the type of management which encourages easy pasture contamination with the parasite eggs. This study has shown that the prevalence of helminth parasitic infection in cattle, sheep and goats in the study area is very high. The most commonly isolated helminths were Strongyloides and Haemonchus species. The source of drinking water, the type of food and the management system of keeping the ruminants were some of the very important factors that greatly influenced the rate of helminth infection among the ruminants in the study area.

\section{REFERENCES}

Anene B.M., Onyekwodiri E.O., Chime A.B. and Anik S.M. (1994). Gastro-intestinal parasites in sheep and goats of southeast Nigeria. Small Ruminants Research, 13, 187-192.

Fabiyi J.P. and Lawal A.O. (1973). "Seasonal fluctuations of nematode infestations in goats in the savannah belt of Nigeria”. Bulletin of Epizootic. Diseases of Africa, 21, 277-285.

Foryet J.W. (2001). Veterinary Parasitology: Reference Manual ( $5^{\text {th }}$ Ed). Blackwell Inc. India. pp 38-39.

Ibukun A.V. and Oludunsin F.O. (2015). Prevalence of Intestinal Helminths and Protozoa Parasites of Ruminants in Minna, North Central, Nigeria. IORS Journal of Agriculture and Veterinary Science, 8 (11), 62-67.

Kanyari P.W.N., Kagira J.M. and Mhoma R.J. (2009). Prevalence and Intensity Endo-parasites in Small Ruminants kept by farmers in Kisumu Municipality. Livestock Research for Rural Development,21(Article no. 202).Retrieved June 8, 2018, from http://www.lrrd.org/lrrd21/11/kany21202.htm

Kassai T. (1999). Veterinary Helminthology Butterworth-Hireman, Reed Education and professional publishing Limited: Oxford, USA. p.260.

Karshima S.N., Maikai B. and Kwaga J.P.K. (2018). Helminths of veterinary and zoonotic importance in Nigerian ruminants: a 46 year meta-analysis (19702016) of prevalence and distribution. Infectious Diseases of Poverty, 7:52.

Mondal M.M. Islam M., Hur J., Lee J. and Baek B. (2000). Examination of gastrointestinal helminth in livestock grazing in grassland of Bangladesh. Korean Journal of Parasitology, 38 (3), 187-190.

N'Depo E.A. (2004). Helminthiasis of the Digestive System of Sheep in Cote D' ivoire. In: First African Veterinary Days (proceedings of conference held at Hammamet, Tunisia, May/June 1987, OIE, Paris), France, 3-6.

Nwosu C.O., Madu P.P. and Richards W.S. (2007). Prevalence and seasonal changes in the population of gastro-intestinal nematode of small ruminants in the semi-arid zone of North-Eastern Nigeria. Veterinary Parasitology, 44 (1-2), 118-124.

Odoi A., Gathuma J.M., Gachuiri C.K. and Omore A. (2007). Risk factors of gastrointestinal nematode parasite infections in small ruminants kept in smallholder mixed farms in Kenya. BMC Veterinary Research, 3:6.

Ogudo U.S., Oluwole A.S., Mogaji H.O., Adeniran A.A., Alabi O.M. and Ekpo U.F. (2015). Gastrointestinal helminth infections in a ruminanat livestock farm in Abeokuta south western Nigeria. Annual Research and Review in Biolog,y 8 (4), 1-8. Article No. ARRB. 18812.

Owhoeli O., Elele K. and Gboeloh L.B. (2014). Prevalence of Gastro-intestinal Helminths in Exotic and Indigenous Goats Slaughtered in Selected Abattoirs in Port-Harcourt, South-South, Nigeria. ChineseJournal ofBiology, e435913.

Regassa F., Sori T., Dhuguma R. and Kiros Y. (2006). Epidemiology of Gastro-intestinal Parasites of Ruminants in Western Oromia, Ethiopia. International Journal ofApplied Research in Veterinary Medicine, 4 (1), 51-57. 
Tsotetsi A.M. and Mbati P.A. (2003). Parasitic Helminths of Veterinary importance in Cattle, Sheep and Goats on Communal farms in the northeastern Free State, South Africa. InternationalJournal ofSouthAfricanVeterinaryAssociation, 74 (2) 45-48.

Urquhart G.M., Aremour J., Dunchan J.L., Dunn A.M. and Jeninis F.W. (1996). Veterinary Parasitology $2^{\text {nd }}$ Ed. The University of Glasgow, Blackwell sciences, Scotland; pp.3-137.
Weber R. (1992). Improved light-microscopical detection of Microsporidia spores in stool and duodenal aspirates. New England Journal ofMedicine,326 (3), 161-166.

Waruiru R.M., Mutune M.N. and Otieno R.O. (2005). Gastrointestinal Parasitic Infections of Machakos District, Kenya. Bulletin ofAnimalHealthand Production inAfrica,53 (3), 25-34. 